УДК 621.036.7

\title{
АНАЛИЗ ЭФФЕКТИВНОСТИ ТЕПЛОУТИЛИЗАЦИОННОЙ \\ УСТАНОВКИ ДЛЯ НАГРЕВАНИЯ И УВЛАЖНЕНИЯ ДУТЬЕВОГО ВОЗДУХА КОТЛОАГРЕГАТА
}

Фиалко Н.М., чЛ.-кор. НАН Украины, Степанова А.И., канд. техн. наук, Пресич Г.А., канд. техн. наук, Гнедаш Г.А., канд. техн. наук

Институт технической теплофизики НАН Украины, ул. Желябова, 2а, Киев, 03580, Украина

Викладено результати аналізу ефективності i оптимізації теплоутилізаційної установки для підігрівання і зволоження дуттьового повітря котлоагрегату. Наведено результати розв'язання оптимізаційної задачі, отримані з урахуванням зміни вологовмісту димових газів і повітря.
Изложены результаты анализа эффективности и оптимизации теплоутилизационной установки для подогрева и увлажнения дутьевого воздуха котлоагрегата. Представлены результаты решения оптимизационной задачи, полученные с учетом изменения влагосодержания дымовых газов и воздуха.

Библ. 5, табл. 2, рис. 3.

Ключевые слова: теплоутилизационная установка, оптимизация, критерий эффективности.

$c_{p}$ - удельная изобарная теплоемкость;

$E$ - эксергетическая мощность;

$G$ - массовый расход теплоносителя;

$i$ - удельная энтальпия;

$m$ - масса;

$p$ - давление;

$p_{s}$ - давление насыщенного пара;

$Q-$ тепловая мощность;

$R$ - газовая постоянная;

$s$ - удельная энтропия;

$T$ - абсолютная температура;

$t$-температура;

$W$ - влагосодержание;

Современные технологии глубокой утилизации теплоты отходящих дымовых газов газопотребляющих котлоагрегатов позволяют повысить тепловую эффективность теплоутилизационной системы и существенно увеличить коэффициент использования теплоты топлива котельной установки. Результативность применения таких технологий в коммунальных котельных повышается в случае обеспечения в теплоутилизационной системе режима глубокой утилизации на протяжении всего отопительного периода. Указанный режим может быть достигнут в комбинированных теплоути- $v$ - удельный объем;

$\mu$ - молекулярная масса;

$\rho-$ плотность;

\section{Индексы верхние:}

дг, вод, воз - дымовые газы, вода, воздух; вл, сух - влажный, сухой.

\section{Индексы нижние:}

вх, вых - входной, выходной параметры;

о - окружающая среда;

$\Pi-$ пар;

пот - потери.

лизационных системах, в которых утилизированная теплота используется не только для подогрева, но и для увлажнения дутьевого воздуха. Современное эффективное водо-и воздухогрейное оборудование, применяемое в таких системах, позволяет успешно осуществить в них необходимый режим глубокой утилизации теплоты. На фоне значительного подорожания топлива перспективность таких мероприятий не вызывает сомнений.

В работе рассматривается комбинированная теплоутилизационная установка, в которой используются поверхностные водо-и воздухо- 
грейный теплообменники и контактный воздухоувлажнительный аппарат (рис. 1).

В указанной установке, предназначенной для подогрева и увлажнения дутьевого воздуха, газоводяные теплообменники включены по газовой стороне в тракт отходящих дымовых газов котлоагрегата, а водяной стороной включены в замкнутый водяной циркуляционный контур. В этот же контур греющей стороной включены воздухогрейные элементы теплоутилизационной системы. Установка содержит поверхностно-контактную подсистему, которая имеет определенные преимущества перед контактно-контактной подсистемой. Это - более глубокое охлаждение дымовых газов в поверхностном конденсационном теплоутилизаторе, повышенный уровень подогрева воды в теплоутилизаторе и соответственно большее увлажнение дутьевого воздуха в контактном аппарате. За счет указанных преимуществ обеспечиваются более высокий экологический эффект, связанный со снижением образования оксидов азота при подаче в топку котлоагрегата увлажненного воздуха, и существенно меньшие по сравнению с применением контактноконтактной подсистемы габариты установки.

Необходимым условием повышения эффективности комбинированных теплоутилизационных установок является их оптимизация. Обоснованный выбор методов решения оптимизационных задач повышает результативность оптимизации, что, в свою очередь, увеличивает эффективность установки, так как позволяет при разработке ее конструкции использовать параметры, максимально приближенные к оптимальным.

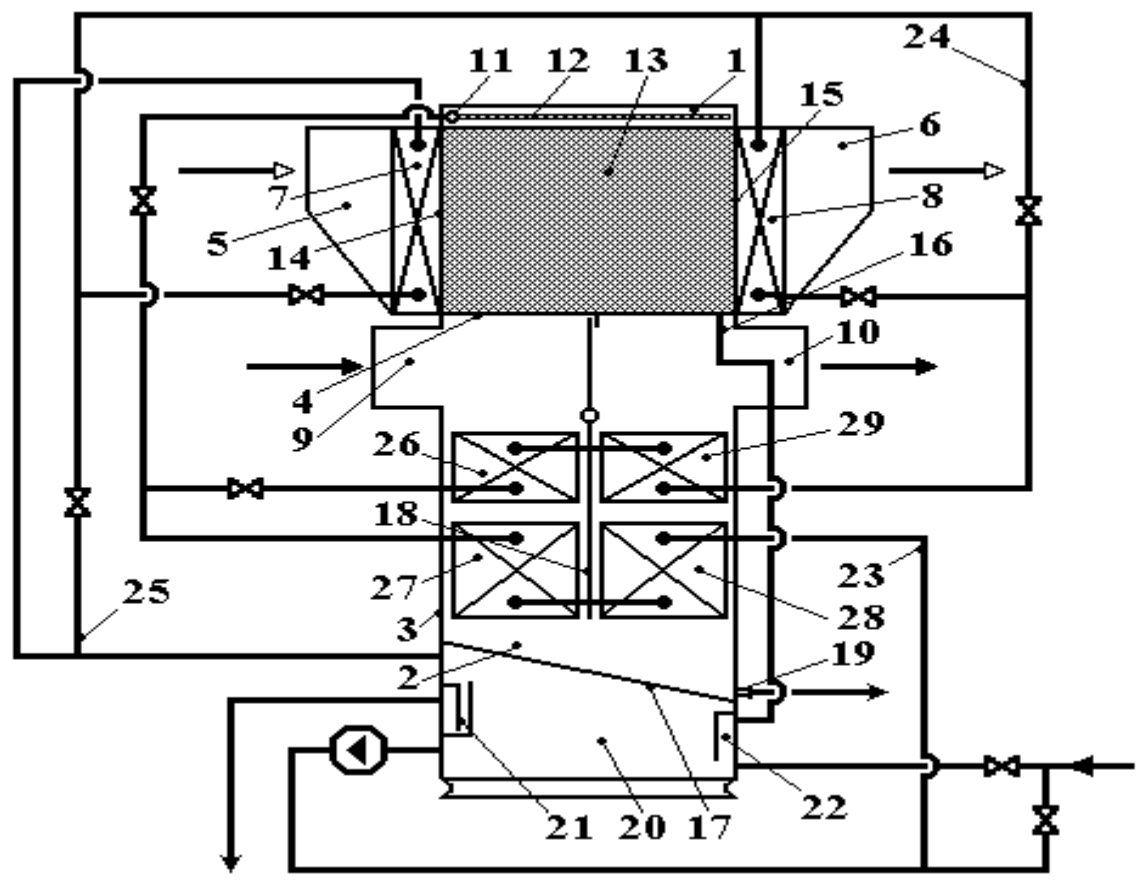

Рис. 1. Принципиальная схема комбинированной теплоутилизационной установки для подогрева и увлажнения дутьевого воздуха:

1, 2 - верхняя и нижняя камеры; 3 -корпус; 4-межкамерная перегородка;

5, 6-патрубки входа и выхода воздуха; 7 - воздухонагреватель; 8 -воздуходогреватель;

9, 10 - патрубки входа и выхода дымовых газов; 11 - коллектор; 12 - оросительные трубы;

13 - тепломассообменная насадка; 14, 15 -ограничительные решетки;

16 - дренажный трубопровод; 17, 18 - перегородки; 19 - патрубок отвода конденсата;

20 - поддон; 21, 22 - гидрозатворы; 23, 24, 25 -соединительные трубопроводы;

26, 27, 28 - секции водоподогревателя (теплоутилизатора); 29 - газоподогреватель. 
Цель работы - повышение эффективности комбинированной теплоутилизационной установки для подогрева и увлажнения дутьевого воздуха путем оптимизации ее параметров.

В работе [1] сформулированы основные положения термодинамической оптимизации теплоутилизационных систем, включающие выбор методов оптимизации таких систем, критериев оценки ее эффективности, которые могли бы служить целевыми функциями оптимизации, а также выбор методов исследования. Для простых теплоутилизационных систем методы термодинамической оптимизации предусматривают определение функциональных зависимостей выбранных критериев эффективности от основных параметров системы. Современные энерготехнологические системы, в том числе и рассматриваемая в работе теплоутилизационная установка, состоят, как правило, из большого количества элементов, вследствие чего установить общие функциональные зависимости для таких систем не представляется возможным. В этих случаях целесообразно использовать специальные методы, среди которых можно выделить структурно-вариантный метод, основанный на эксергетическом подходе, и метод многоуровневой оптимизации $[2,3]$.

Для теплоутилизационных систем структурно-вариантный метод оптимизации предполагает их моделирование в виде структурной схемы, в которой устанавливаются эксергетические потоки между отдельными элементами системы; выполнение тепловых и эксергетических расчетов, позволяющих определить элемент или совокупность элементов, изменение эксергетических потерь в которых наиболее сильно влияет на эффективность установки в целом; оптимизацию выделенных элементов и включение элементов с оптимальными параметрами в общую схему установки.

Метод многоуровневой оптимизации дает возможность свести общую многокритериальную и многопараметрическую оптимизационную задачу к более простым локальным взаимосогласованным оптимизационным задачам каждого уровня. Он включает разделение теплоутилизационной установки на несколько уровней оптимизации, разработку блок-схемы многоуровневой оптимизации и схемы рекурсивного обхода уровней, выбор методов построения математических моделей, рекурсивных целевых функций и варьируемых параметров для каждого уровня оптимизации, а также определение оптимальных параметров установки.

В работе [4] на примере оптимизации теплоутилизационной установки для котельных, предназначенной для нагревания обратной теплосетевой воды, показаны преимущества метода многоуровневой оптимизации по сравнению со структурно-вариантным методом. Целесообразно провести сравнительный анализ указанных методов на примере более сложной теплоутилизационной установки. Такой установкой является исследуемая комбинированная теплоутилизационная установка для подогрева и увлажнения дутьевого воздуха.

В соответствии с основными положениями термодинамической оптимизации теплоутилизационных систем для анализа эффективности и оптимизации указанной теплоутилизационной установки были реализованы все необходимые этапы. В качестве целевых функций оптимизации использовались тепло-эксергетический и эксерго-технологический критерии эффективности: $\varepsilon=E_{\text {пот }}^{\text {внут }} / Q, k_{e x}^{\mathrm{T}}=E_{\text {пот }}^{\text {внут }} \cdot m / Q^{2}, \quad$ а в качестве метода исследования - балансовый метод эксергетического анализа. Следует отметить, что меньшие значения указанных критериев соответствуют более высокой эффективности теплоутилизационной установки.

В рамках структурно-вариантного метода теплоутилизационная установка была представлена в виде ряда дискретных взаимосвязанных эксергетическими потоками элементов более простой структуры (рис. 2).

В соответствии со структурной схемой выполнены тепловые и эксергетические расчеты, позволившие выделить два элемента, составляющие поверхностно-контактную подсистему - поверхностный конденсационный водоподогреватель (теплоутилизатор) и контактный подогреватель и увлажнитель дутьевого воздуха, изменение эксергетических потерь в которых наиболее сильно влияет на изменение эффективности системы в целом. Проведена 
оптимизация указанных элементов теплоутилизационной системы. Необходимые для решения оптимизационных задач функциональные зависимости критериев эффективности от основных параметров элементов получены с использованием статистических методов планирования эксперимента. Эти методы просты в использовании, предполагают небольшой объем исследований и достаточно надежны, поскольку достоверность результатов оценивается с помощью соответствующих критериев на каждом этапе решения задачи [5]. Поверхностный конденсационный водоподогреватель и контактный подогреватель и увлажнитель дутьевого воздуха с оптимальными параметрами использованы в качестве составляющих элементов в теплоутилизационной установке и для указанной установки рассчитаны значения тепло-эксергетического и эксерго-технологического критериев эффективности, приведенные далее.

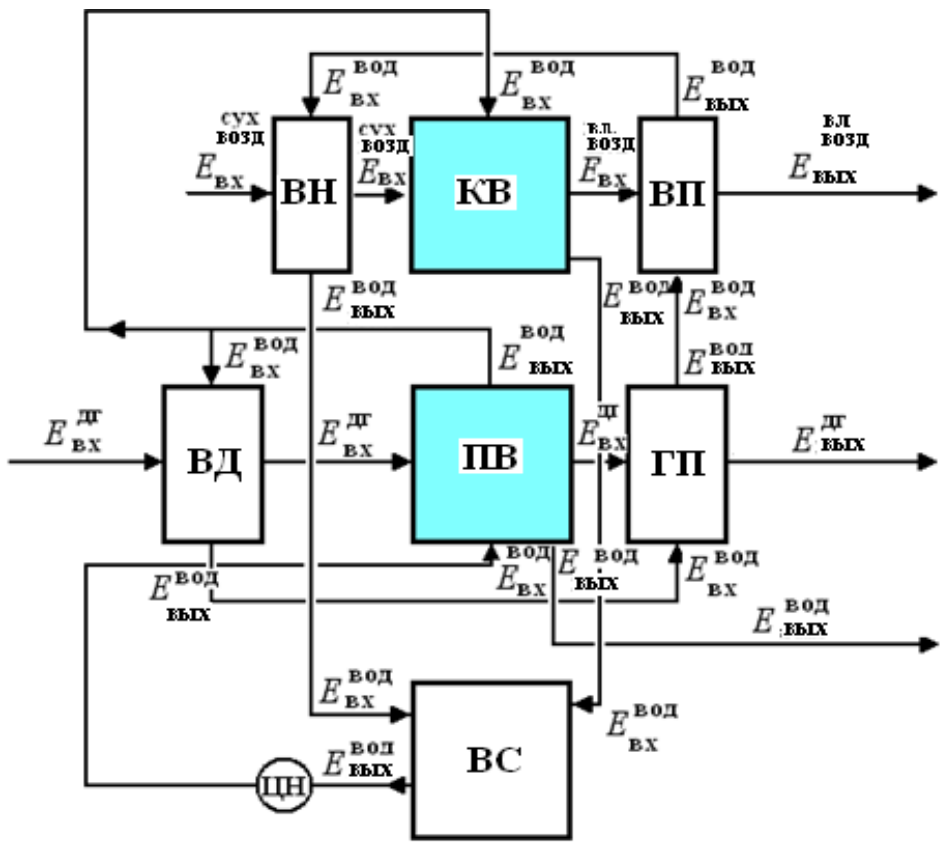

Рис. 2. Структурная схема комбинированной теплоутилизационной установки для подогрева и увлажнения дутьевого воздуха с обозначением эксергетических потоков между элементами:

ВН - воздухонагреватель; КВ - контактный подогреватель и увлажнитель воздуха; ВП - воздуходогреватель; ВД - вододогреватель;

ПВ - поверхностный водоподогреватель (теплоутилизатор); ГП - газоподогреватель; ВС - водосборник; ЦН - циркуляционный насос.

Для решения задачи многоуровневой оптимизации проведено разделение теплоутилизационной установки на пять уровней оптимизации, выбраны целевые функции оптимизации и варьируемые параметры для каждого уровня, разработана блок-схема и схема рекурсивного обхода уровней оптимизации (табл. 1, рис. 3 ).

Как и в случае структурно-вариантного метода, в качестве методов построения математических моделей каждого уровня исполь- зовались статистические методы планирования эксперимента. При этом в качестве переменных параметров для данного уровня оптимизации использовались варьируемые параметры объекта данного уровня, а в качестве постоянных параметров - оптимальные параметры, которые являются результатами решения локальных оптимизационных задач других уровней. Для данной задачи схема рекурсивного обхода уровней оптимизации предусматривает ветвление на верхнем 
уровне, что обеспечивает в определенных условиях прекращение рекурсии, и ветвление на втором, третьем и четвертом уровнях для введения в действие параллельных рекурсий, когда на одной рекурсивной ветви делается несколько рекурсивных вызовов.

Табл. 1. Целевые функции и варьируемые параметры для каждого уровня оптимизации

\begin{tabular}{|c|c|c|c|}
\hline № & Уровень & Целевая функция & Варьируемые параметры \\
\hline 1 & $\begin{array}{c}\text { Теплоутилизационная } \\
\text { система }\end{array}$ & $k_{e x}^{\mathrm{T}}=E_{\text {пот }}^{\text {внут }} \cdot m / Q^{2}$ & $\begin{array}{l}\text { Расход воды в циркуляционном контуре, } \\
\text { влагосодержание дымовых газов на входе, } \\
\text { температура воды на входе в водоподогреватель. }\end{array}$ \\
\hline 2 & $\begin{array}{c}\text { Водоподогреватель } \\
\text { поверхностный } \\
\text { конденсационный }\end{array}$ & $k_{e x}^{\mathrm{T}}=E_{\text {пот }}^{\text {внут }} \cdot m / Q^{2}$ & $\begin{array}{l}\text { Отношение влагосодержания дымовых газов } \\
\text { на входе и выходе, отношение чисел } \\
\text { Рейнольдса дымовых газов и воды. }\end{array}$ \\
\hline 3 & $\begin{array}{c}\text { "Сухая" зона } \\
\text { водоподогревателя }\end{array}$ & $\varepsilon=E_{\text {пот }}^{\text {внут }} / Q$ & $\begin{array}{l}\text { Геометрические параметры труб: } \\
\text { высота и толщина ребра, межреберный шаг. }\end{array}$ \\
\hline 4 & $\begin{array}{c}\text { "Мокрая" зона } \\
\text { водоподогревателя }\end{array}$ & $\varepsilon=E_{\text {пот }}^{\text {внут }} / Q$ & $\begin{array}{l}\text { Геометрические параметры труб: } \\
\text { высота и толщина ребра, межреберный шаг. }\end{array}$ \\
\hline 5 & $\begin{array}{c}\text { Воздухоувлажнитель } \\
\text { контактный }\end{array}$ & $k_{e x}^{\mathrm{T}}=E_{\text {пот }}^{\text {внут }} \cdot m / Q^{2}$ & $\begin{array}{l}\text { Отношение влагосодержания воздуха на входе } \\
\text { и выходе, плотность орошения и удельная } \\
\text { площадь поверхности насадки. }\end{array}$ \\
\hline
\end{tabular}

Используемые на определенном уровне критерии эффективности, выступающие в качестве целевых функций оптимизации, были выбраны из расчета, что каждый из критериев наиболее чувствителен к варьируемым параметрам именно данного уровня.

В указанной комбинированной схеме отходящие дымовые газы котлоагрегата, работающего со среднегодовой нагрузкой 60 \%, характеризуются повышенным начальным влагосодержанием $(0,15 \ldots 0,30$ кг/кг с.г.), которое может уменьшаться в процессе их прохождения через поверхност-

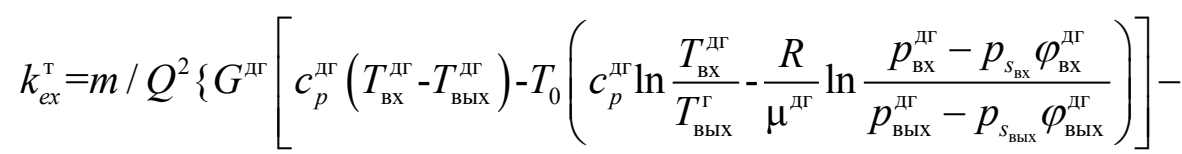

$$
\begin{aligned}
& -G^{\text {дг }} W_{\text {вых }}^{\text {дг }}\left[c_{p}^{\text {пा }}\left(T_{\text {вых }}^{\text {дг }}-T_{0}\right)-T_{0}\left(c_{p}^{\text {п }} \ln \frac{T_{\text {вых }}^{\text {дг }}}{T_{0}}-\frac{R}{\mu^{\text {п }}} \ln \frac{\rho_{\text {вых }}^{\text {п }} p_{s_{\text {вых }}} v_{\text {вых }}^{\prime \prime} W_{\text {вых }}}{\rho_{0}^{\text {п }} p_{s_{0}} v_{0}^{\prime \prime} \varphi_{0}\left(1+W_{\text {вых }}\right)}\right)\right]+ \\
& +G^{\text {дг }} W_{\mathrm{BX}}^{\text {дг }}\left[c_{p}^{\mathrm{\Pi}}\left(T_{\mathrm{Bx}}^{\text {дг }}-T_{0}\right)-T_{0}\left(c_{p}^{\mathrm{\Pi}} \ln \frac{T_{\mathrm{BX}}^{\text {дг }}}{T_{0}}-\frac{R}{\mu^{\mathrm{I}}} \ln \frac{\rho_{\mathrm{Bx}}^{\mathrm{\Pi}} p_{s_{\mathrm{Bx}}} v_{\mathrm{Bx}}^{\prime \prime} W_{\mathrm{BX}}}{\rho_{0}^{\mathrm{\Pi}} p_{s_{0}} v_{0}^{\prime \prime} \varphi_{0}\left(1+W_{\mathrm{Bx}}\right)}\right)\right]- \\
& \left.-G^{\text {вод }}\left[\left(i_{\text {вых }}^{\text {вод }}-i_{\mathrm{BX}}^{\text {вод }}\right)-T_{0}\left(s_{\text {вых }}^{\text {вод }}-S_{\text {вХ }}^{\text {вод }}\right)\right]\right\} .
\end{aligned}
$$


Для контактного теплообменника (подогревателя и увлажнителя воздуха):

$$
\begin{aligned}
& k_{e x}^{\mathrm{T}}=m / Q^{2}\left\{G^{\text {вод }}\left[\left(i_{\text {вх }}^{\text {вод }}-i_{\text {вых }}^{\text {вод }}\right)-T_{0}\left(s_{\text {вх }}^{\text {вод }}-s_{\text {вых }}^{\text {вод }}\right)\right]-\right.
\end{aligned}
$$

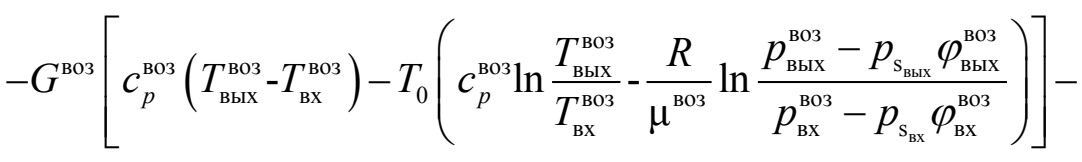

$$
\begin{aligned}
& -G^{\mathrm{B} 03} W_{\mathrm{BX}}^{\mathrm{B} 03}\left[c_{p}^{\mathrm{\Pi}}\left(T_{\mathrm{Bx}}^{\mathrm{B} 03}-T_{0}\right)-T_{0}\left(c_{p}^{\mathrm{\Pi}} \ln \frac{T_{\mathrm{BX}}^{\mathrm{B} 03}}{T_{0}}-\frac{R}{\mu^{\mathrm{\Pi}}} \ln \frac{\rho_{\mathrm{BX}}^{\mathrm{\Pi}} p_{\mathrm{s}_{\mathrm{BX}}} v_{\mathrm{BX}}^{\mathrm{\prime}} W_{\mathrm{BX}}}{\rho_{0}^{\mathrm{I}} p_{\mathrm{s} 0} v_{0}^{\mathrm{I}} \varphi_{0}\left(1+W_{\mathrm{BX}}\right)}\right)\right]+ \\
& \left.+G^{\text {во3 }} W_{\text {вых }}^{\text {воз }}\left[c_{p}^{\text {п }}\left(T_{\text {вых }}^{\text {воз }}-T_{0}\right)-T_{0}\left(c_{p}^{\text {пар }} \ln \frac{T_{\text {вых }}^{\text {во3 }}}{T_{0}}-\frac{R}{\mu^{\text {П }}} \ln \frac{\rho_{\text {вых }}^{\text {п }} p_{\text {вых }} v_{\text {вых }}^{\prime \prime} W_{\text {вых }}}{\rho_{0}^{\text {п }} p_{\text {s0 }} v_{0}^{\prime \prime} \varphi_{0}\left(1+W_{\text {вых }}\right)}\right)\right]\right\} .
\end{aligned}
$$

Для исследуемой теплоутилизационной установки на основе метода многоуровневой оптимизации получены оптимальные значения режимных и конструкционных параметров, а также рассчитаны значения критериев эффективности. Значения эксерго-технологического критерия эффективности при расчете структурно-вариантным методом составляло $k_{e x}^{\mathrm{T}}=$ $=0,572$ кг/кВт, а методом многоуровневой оптимизации $-k_{e x}^{\mathrm{T}}=0,554$ кг $/$ кВт.

Таким образом, эффективность исследуемой теплоутилизационной установки, рассчитанная методом многоуровневой оптимизации, как и в случае теплоутилизационной установки, исследованной в работе [4], на $3 \%$ выше эффективности, рассчитанной структурно-вариантным методом. Этот факт свидетельствует о том, что при применении методики многоуровневой оптимизации полученные режимные и конструкционные параметры максимально приближены к оптимальным. Учет технологических особенностей и специфики эксплуатации теплоутилизационного оборудования в конкретных условиях приводит к необходимости нахождения оптимальной области изменения параметров, которая определяетсяна основе их конкретных оптимальных значений, полученных методом многоуровневой оптимизации. Ширина этой области зависит от указанных особенностей теплоутилизационной системы и от степени изменения критериев эффективности в пределах области. В таблице 2 приведены результаты решения оптимизационной задачи методом многоуровневой оптимизации.
1. На примере комбинированной теплоутилизационной установки с применением водо- и воздухогрейного оборудования показано, что эксергетическая эффективность сложных теплоутилизационных установок, оптимизированных с использованием метода многоуровневой оптимизации, в среднем, на 2,5 \% выше эффективности установок, оптимизированных с использованием структурно-вариантного метода.

2. В рамках использования метода многоуровневой оптимизации для исследуемой теплоутилизационной установки разработаны блок-схема многоуровневой оптимизации, включающая пять уровней оптимизации, и схема рекурсивного обхода уровней с необходимыми ветвлениями на каждом уровне.

3. Для расчета эксергетических критериев эффективности теплоутилизационной установки предложены зависимости, в которых учитывалось изменение влагосодержания дымовых газов после их прохождения через поверхностный конденсационный водоподогреватель и изменение влагосодержания воздуха после его прохождения через контактный воздухоувлажнитель.

4. На основе метода многоуровневой оптимизации получены оптимальные значения режимных и конструкционных параметров комбинированной теплоутилизационной установки с применением водо- и воздухогрейного оборудования, использование которых при разработке конструкции установки позволило увеличить ее эффективность на 2,5\%. 


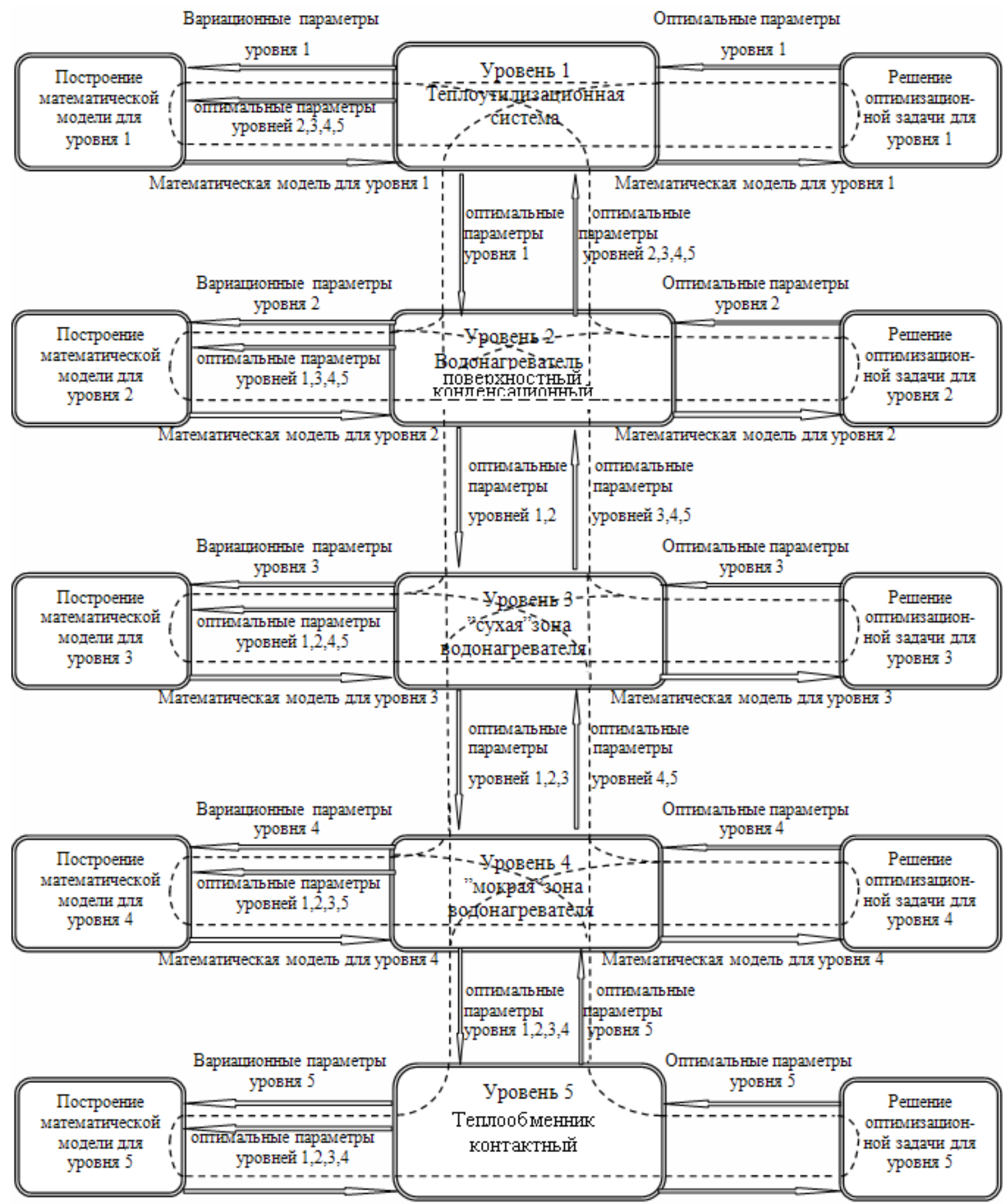

Математкческая модеть дтя уровни 5

Математкческая модеть дтя уровня 5

\section{Рис. 3. Блок-схема многоуровневой оптимизации теплоутилизационной установки для подогрева и увлажннения дутьевого воздуха


Табл. 2. Результаты многоуровневой оптимизации теплоутилизационной установки для подогрева и увлажнения дутьевого воздуха

\begin{tabular}{|c|c|c|c|c|}
\hline Уровень & $\begin{array}{c}\text { Варьируемые } \\
\text { параметры }\end{array}$ & $\begin{array}{c}\text { Обо- } \\
\text { зна- } \\
\text { чение }\end{array}$ & $\begin{array}{c}\text { Размер- } \\
\text { ность }\end{array}$ & $\begin{array}{l}\text { Оптималь- } \\
\text { ные } \\
\text { значения }\end{array}$ \\
\hline \multirow{3}{*}{$\begin{array}{l}\text { Теплоутилизационная } \\
\text { система }\end{array}$} & Расход воды в циркуляционного контуре & $G^{\text {вод }}$ & кг/c & $0,8 \ldots 1,1$ \\
\hline & Влагосодержание дымовых газов на входе & $W_{\mathrm{Bx}}$ & Кг/Кг с.г. & $0,18 \ldots 0,20$ \\
\hline & Температура воды на входе в водоподогреватель & $t_{\mathrm{BX}}$ & ${ }^{0} \mathrm{C}$ & $30 \ldots 32$ \\
\hline \multirow{2}{*}{$\begin{array}{l}\text { Водоподогреватель } \\
\text { поверхностный } \\
\text { конденсационный }\end{array}$} & $\begin{array}{l}\text { Отношение влагосодержания дымовых газов } \\
\text { на входе и выходе }\end{array}$ & $\frac{W_{\text {Bर }}^{\text {дг }}}{W_{\text {Bux }}^{\text {дा }}}$ & - & $3,0 \ldots 3,3$ \\
\hline & $\begin{array}{l}\text { Отношение чисел Рейнольдса дымовых газов } \\
\text { и воды }\end{array}$ & $\frac{\mathrm{Re}^{\mathrm{Ar}}}{\operatorname{Re}^{\mathrm{BOA}}}$ & - & $0,3 \ldots 1,0$ \\
\hline \multirow{3}{*}{$\begin{array}{l}\text { “Сухая” зона } \\
\text { водоподогревателя }\end{array}$} & Высота ребра & $h$ & MM & $10,0 \ldots 11,0$ \\
\hline & Толщина ребра & $b$ & MM & $0,4 \ldots 0,6$ \\
\hline & Межреберный шаг & $s$ & MM & $3,0 \ldots 3,5$ \\
\hline \multirow{3}{*}{$\begin{array}{l}\text { “Мокрая” зона } \\
\text { водоподогревателя }\end{array}$} & Высота ребра & $h$ & MM & $8,0 \ldots 10,0$ \\
\hline & Толщина ребра & $b$ & MM & $0,4 \ldots 0,6$ \\
\hline & Межреберный шаг & $s$ & MM & $4,0 \ldots 5,0$ \\
\hline \multirow{3}{*}{$\begin{array}{l}\text { Контактный } \\
\text { воздухоувлажнитель }\end{array}$} & $\begin{array}{l}\text { Отношение влагосодержания воздуха } \\
\text { на входе и выходе }\end{array}$ & $\frac{W_{\mathrm{BX}}^{\mathrm{BO}}}{W_{\mathrm{Bdx}}^{\mathrm{Bo3}}}$ & - & $0,05 \ldots 0,06$ \\
\hline & Плотность орошения насадки & $Z$ & $\mathrm{M}^{3} / \mathrm{M}^{2} \mathrm{Y}$ & $10,0 \ldots 15,0$ \\
\hline & Удельная площадь поверхности насадки & $f$ & $\mathrm{M}^{2} / \mathrm{M}^{3}$ & $90,0 \ldots 100,0$ \\
\hline
\end{tabular}

\section{ЛИТЕРАТУРА}

1. Фиалко Н.М., Шеренковский Ю. В., Степанова А.И., Пресич Г.А., Навродская Р.А., Малеикая О.Е., Гнедаш Г.А. Термодинамическая оптимизация и анализ эффективности теплоутилизационной системы котельных агрегатов // Промышленная теплотехника. - 2012. - Т. 34, №2. - С. $59-66$.

2. Эксергетический расчет технических систем. Справочное пособие. Под ред. Долинского А.А.: Наукова Думка. - 1991. $360 \mathrm{c}$.

3. Бойко А.В., Говорущченко Ю.Р., Усатый
A.П., Руденко А.С. Методика и алгоритм оптимизации проточных частей осевых турбин с учетом режимов эксплуатации // Тяжелое машиностроение. - 2009, №9. - С. $11-15$.

4. Фиалко Н.M., Степанова А.И., Навродская Р.А., Шеренковский Ю. В. Эффективность теплоутилизационной установки для котельных, оптимизированной различными методами // Промышленная теплотехника. - 2014. - Т.36, №1. - C.41-47.

5. Налимов В.В. Теория эксперимента. М.: Наука, 1971. - 207 с. 


\section{THE EFFICIENCY ANALISIS OF HEAT UTILIZATION INSTALASION FOR HEATING AND HUMIDIFYING OF COMBUSTION AIR OF BOILER PLANT}

Fialko N., Stepanova A., Presich G.,Gnedash G.

Institute of Engineering Thermophysics of the National Academy of Sciences of Ukraine, vul. Zhelyabova, 2a, Kyiv, 03680, Ukraine

There are exposed results of comparative analysis for efficiency of combined heatutilyzing instalation for boilers, used for heating and damping of combustion air, which was optimized due to use of structure - variant method and method of multilevel. The solution of the problem of optimization obtained by the method of multilevel optimization is presented. The changes of content the smoke gases and air are taken into account. References 5, tables 2, figures 3.

Key words: thermoutilyzers, optimizing, criteria of efficiency.
1. Fialko N., Sherenkovsky J., Stepanova A., Navrodska R.,Presich G., Maletska O.,Gnedash $G$. Thermodynamical optimization and analysis of efficiency for heatutilizing systems of boiler plants // Promyshlennaya teplotekhnika. - 2012. V. 34, № 2. - P. 59 - 66. (Rus.)

2. Exergy calculanion of technical systems. Reference book. Edited by Dolinsky A. Kyiv: "Naukova dumka". - 1991. - 360p.

3. Boiko A., Govorutchenko J., Usatu A., Rudenko $A$. Methodology and alhorithm of optimithation of turbine setting with taking into account the condition of use // Tiageloe maghinostroenie. - 2009, №9. - P. 11 - 15.

4. Fialko N., Stepanova A., Navrodska R., Sherenkovsky J. Efficiency for heatutilizing systems of boiler instalation, for optimization of method of different types // Promyshlennaya teplotekhnika. - 2014. - V. 36, № 1. - P. 41-47. (Rus.)

5. Nalimov $V$. Theory of experiment. - M.: Nauka, 1971. - 207 c. 